\title{
Processos de democracia direta: sim \\ ou não? Os argumentos clássicos à \\ luz da teoria e da prática
}

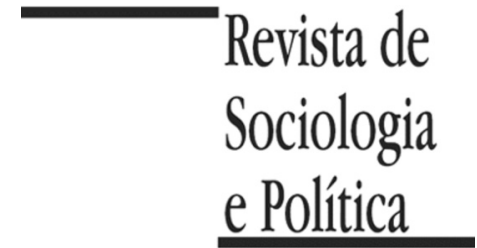

\author{
Rolf Rauschenbach
}

RESUMO

Regularmente surgem controvérsias sobre os processos de democracia direta, dos quais os mecanismos mais frequentes são a iniciativa popular, o plebiscito e o referendo. Por um lado, há autores que defendem a posição de que essas instituições tornam o jogo político mais lento, caro, confuso e ilegítimo; outros defendem a posição contrária e argumentam que processos de democracia direta são fundamentais para os cidadãos e a qualidade da democracia. O presente estudo analisa esse tema em torno de sete questões, baseadas em considerações teóricas e pesquisas empíricas: 1. A questão entre o minimalismo e o maximalismo democrático; 2. A concorrência entre maioria e minoria; 3. A concorrência entre as instituições representativas e os processos de democracia direta; 4. A questão da competência dos cidadãos; 5. A questão dos efeitos colaterais dos processos de democracia direta; 6 . A questão do tamanho do eleitorado; 7. A questão dos custos dos processos de democracia direta. As sete questões são analisadas a partir de uma revisão bibliográfica que considera tanto fontes nacionais como internacionais. O estudo mostra que os processos de democracia direta podem ser um complemento para as instituições representativas em um sistema democrático. O bom desempenho dos plebiscitos, referendos e iniciativas populares depende tanto da regulamentação destes como também do desempenho das outras instituições políticas e da situação socioeconômica de um país. O estudo permite ampliar e aprofundar o debate sobre processos de democracia direta no Brasil.

PALAVRAS-CHAVE: Instituições democráticas; processos de democracia direta; iniciativa popular; plebiscito; referendo; representação

Recebido em 15 de Março de 2013. Aprovado em 8 de Agosto de 2013.

\section{Introdução ${ }^{1}$}

${ }^{1}$ Gostaria de agradecer aos pareceristas anônimos da Revista de Sociologia e Política por sua contribuição para este ensaio.

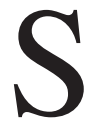
eria de fato uma boa ideia consultar a população não somente em eleições, mas também a respeito de questões específicas, que podem ser respondidas com um simples "sim" ou "não"? Essa pergunta surge regularmente, tanto no campo nacional como internacional. O motivo pode ser uma consulta popular agendada ou ocorrida, falhas das instituições representativas ou a tentativa de aumentar ou diminuir os mecanismos de participação em geral. No presente estudo, foca-se processos de democracia direta que podemos definir como instituições publicamente reconhecidas, nas quais os cidadãos decidem ou opinam sobre questões específicas por meio de consultas populares secretas e universais (Altman 2012, p. 2). Os exemplos mais comuns são o plebiscito, o referendo e a iniciativa popular. Não se considera os mecanismos da petição e do recall como processos de democracia direta. Evita-se o termo "democracia direta" e fala-se sempre em "processos de democracia direta", para assinalar que se considera essas instituições como parte de um conjunto maior e não como o sistema democrático em si. Nesse sentido, as considerações normativas deste trabalho, no que diz respeito aos processos de democracia direta, demonstram que não se percebe neles um valor em si, mas, 
sim um meio que permite, no melhor dos casos, produzir decisões legítimas (Gurza-Lavalle 2011).

O presente estudo pretende contribuir para o enriquecimento da literatura brasileira, na qual os processos de democracia direta têm uma importância relativamente marginal e comparações internacionais são raras. Nessa literatura, podem ser destacados quatro grupos de trabalhos dedicados ao assunto. Em primeiro lugar, poucos títulos foram publicados logo após a proclamação da Constituição de 1988. Moisés (1990) e Benevides de Mesquita (1991) discutem a questão da participação e representação de um ponto de vista teóriconormativo e concluem que os processos de democracia direta podem contribuir consideravelmente para a democratização do Brasil e a criação de uma cidadania ativa. No entanto, as previsões desses autores sobre o futuro do Brasil são relativamente pessimistas, tendo em vista um regulamento que dificulta a realização de consultas populares.

Um segundo grupo de publicações é produzido por juristas que analisam em detalhe a legislação brasileira sobre os processos de democracia direta. Todos os autores afirmam que o regulamento desses mecanismos não é claro e tampouco respalda adequadamente o direito do cidadão à participação política. A maioria desses estudos são teses de mestrado ou doutorado e não foi publicada oficialmente (Carneiro 2001; Ávila de Brito 2002; Auad et al. 2004; Garcia Navarro 2004; Galante Lesqueves 2006; Vogel 2006; Zart 2007).

Um terceiro grupo investiga o referendo de 2005 a partir de diferentes perspectivas. Neste caso, vale mencionar uma coleção de ensaios organizados por Inácio, Novaes e Anastásia (2006). Nessa coleção, são levantadas, entre outras questões, a participação do poder Executivo no referendo (Inácio 2006), a tensão entre a participação popular e as instituições de representação (Anastásia, Inácio \& Novais 2006; Araújo \& Santana 2006; Correa \& Nunes 2006), e a importância da mídia e da propaganda (Castro 2006; Fuks \& Novais 2006; Fuks \& Paiva 2006). Esses autores concluíram que o referendo de 2005 revelou a fragilidade da instituição e que tanto o sistema político como a sociedade brasileira ainda demonstram lacunas em sua capacidade de usufruir plenamente dos benefícios de um referendo. Outros estudos aprofundam essa análise. Menezes Boelhouwer e Dias (2009) abordaram a cobertura do referendo nos jornais Folha de S. Paulo e $O$ Globo, alegando que as cartas dos leitores eram mais frequentes do que as reportagens sobre o assunto e que a maioria dessas cartas optaram pelo não. Um painel de pesquisa com eleitores avaliou o impacto das campanhas e concluiu que o referendo foi vencido por meio da propaganda política negativa que criou um clima de medo (Viega \& Avi dos Santos 2008). Um outro estudo analisa os municípios brasileiros e demonstra a correlação positiva entre a taxa de homicídios e o não (Araujo Junior et al. 2007). Por fim, Mendonça (2009) analisa a qualidade deliberativa das campanhas, enfatizando a importância da cooperação positiva entre os adversários.

Um quarto grupo reúne publicações recentes e com abordagens mais gerais. O ensaio de Dantas (2008) faz um balanço sobre os 20 anos de participação política sob a Constituição de 1988. Para o autor, os resultados são ambivalentes. Por um lado, não foi confirmado o otimismo inicial com relação à participação política e, de outro, podem ser identificadas várias inovações institucionais, como o orçamento participativo ou os conselhos gestores (idem). Mendes Vitale Ramos (2007) argumenta na mesma direção, focando especificamente no déficit democrático. Já Alves (2011) procura responder como a fragmentação partidária, a polarização do sistema político e o uso de 
processos de democracia direta na América Latina estão correlacionados. Em outro estudo, a mesma autora apresenta um balanço sobre o uso dos mecanismos de democracia direta entre 1988 e 2008 (Alves 2010). Já que é da competência do Congresso Nacional convocar consultas populares, Alves analisa em particular todos os 156 projetos de Decretos Legislativos com objetivo de convocar plebiscitos e referendos e confirma os empecilhos institucionais que dificultam o uso destes mecanismos. Peterlevitz (2011) não se preocupa com o funcionamento das instituições da democracia direta em si, mas parte delas para avaliar a qualidade, em termos gerais, da participação política em um país. Rauschenbach (2011), também oferece um relato completo e resumido sobre processos de democracia direta em nível federal.

A escassa produção bibliográfica brasileira sobre os processos de democracia direta certamente é devida ao raro uso desses mecanismos. Desde a proclamação da nova Constituição, houve em nível federal cinco iniciativas populares que foram apresentadas ao Congresso Nacional, um plebiscito (1993) e um referendo (2005). Em nível estadual, houve um referendo (Acre, em 2010) e dois plebiscitos (Pará, em 2011). Em nível municipal, não existe nenhum levantamento. Por outro lado, a ausência do tema representa também certa surpresa. Afinal, estabeleceu-se no Brasil, nas últimas duas décadas, um amplo debate sobre participação política e as nova instituições participativas, como o orçamento participativo, conselhos e conferências. Essa vertente ignora em grande parte as instituições da democracia direta e quase não dialoga com a respectiva literatura, como mostra, por exemplo, a - em si excelente publicação do IPEA sobre a efetividade as instituições participativas no Brasil (Rocha Pires 2011). Pelo menos em parte, isso pode ser atribuído ao fato de as novas instituições participativas terem criado canais de representação extraparlamentar (Gurza Lavalle \& Isunza Vera 2011, p. 113), conceitualmente alheios aos processos de democracia direta.

Em suma, podemos concluir que a literatura brasileira aborda os processos de democracia direta de maneira normativa ou foca em questões relativamente específicas e descritivas. Faltam ponderações que considerem tanto os argumentos normativos e empíricos, falta também uma visão comparativa. O presente trabalho pretende preencher essa lacuna, dialogando com a literatura internacional. Ficará visível que a bibliografia internacional sobre os processos de democracia direta trata as diversas dimensões desse fenômeno e alimenta-se tanto de vertentes normativas, institucionalistas, da escola de racional choice, entre outras.

O estudo é organizado em sete questões que permitem situar os processos de democracia direta normativamente no debate teórico sobre democracia, explicitar as implicações institucionais desses mecanismos e destacar os principais desafios existentes neles. Iniciar-se-á o debate com a questão entre o minimalismo e o maximalismo democrático, que define a configuração fundamental de um sistema democrático. Isso levará à questão sobre a concorrência entre maioria e minoria. As escolhas sobre a geração e o tratamento de maiorias e minorias não dizem somente a respeito dos processos de democracia direta, mas ao conjunto completo das instituições democráticas. Elas são particularmente relevantes no contexto dos processos de democracia direta, já que esses mecanismos geram por definição maiorias e minorias explícitas. Como os processos de democracia direta são somente um complemento às diversas instituições democráticas, coloca-se a questão sobre a relação entre elas. Por isso, aborda-se, na terceira seção, a concorrência entre as instituições representativas e os processos de democracia direta. Em seguida, trata-se de quatro 
desafios, que partem dos processos de democracia: a competência dos cidadãos, o tamanho do eleitorado, os efeitos colaterais e os custos. Como essas instituições permitem intervenções imediatas dos cidadãos no processo político, questiona-se a competência deles. Afinal, as consequências de decisões populares são tão graves como as de decisões parlamentares ou do goveno. Além do questionamento sobre a competência individual dos eleitores, surge regularmente a alegação de que o tamanho do eleitorado representa um fator importante no empenho dos processos de democracia direta. Na quinta seção, procura-se respostas à dimensão quantitativa de consultas populares. Enquanto a geraçãoe de legitimidade pelos processos de democracia direta normalmente não é colocada em dúvida, levanta-se a questão sobre os efeitos colaterais dos processos de democracia (seção seis) e dos custos (seção sete). Essas abordagens permitirão uma avaliação mais completa do tema deste trabalho.

A metodologia aplicada neste estudo é uma revisão bibliográfica, que leva em consideração publicações com um viés normativo ou teórico, como também empírico.

A investigação mostra que processos de democracia direta podem ser uma boa ferramenta para produzir decisões legítimas. Mas mostra, também, que o benefício de processos de democracia direta depende da institucionalização específica desses mecanismos. Ademais, este estudo mostrará que o contexto institucional geral e os fatores socioeconômicos igualmente influenciam o desempenho dos processos de democracia direta. A resposta à pergunta "Processos de democracia direta: sim ou não?" é então relativa: no curto prazo, eles dependem das circunstâncias. No longo prazo, podem ser um complemento importante às instituições democráticas.

\section{Os argumentos em favor e contra os processos de democracia direta}

O debate entre os que argumentam em favor das instituições representativas e contra os processos de democracia direta é tão velho como a ideia da democracia em si. Platão já pensava que uma república somente pode ser governada pela elite; ele posicionou-se claramente contra o modelo de Atenas, onde todos os cidadãos participavam na tomada de decisões políticas. Vale ressaltar que, naquela época, a categoria do cidadão não incluía mulheres nem escravos. Aristóteles promovia o conceito da constituição mista, que unia elementos monárquicos, aristocráticos e democráticos; ele admitia uma participação parcial da população. Mais tarde, ao referir-se à Revolução Francesa, Edmund Burke alegou que a participação da população levara a uma simplificação excessiva das questões políticas. A posição de Montesquieu era similar: para ele, faltava a competência do cidadão para justificar sua participação política. Na mesma época, Rousseau argumentava em favor da participação dos cidadãos, já que todos nascem livres. Seria fácil estender essa lista de nomes ilustres; como veremos, o debate continua até os dias atuais. Os argumentos são analisados sistematicamente nas próximas seções. Aqui cabem ainda algumas constatações gerais:

O fato de o debate não ter sido concluído até hoje não é preocupante em si. No caso da democracia, se trata de um conceito contestado (Gallie 1956, p. 169). Isso quer dizer que, por motivos epistemológicos, não é de se esperar que um dia surja uma definição aceita universalmente. Sempre haverá controvérsia. Além disso, a democracia é caracterizada por vários paradoxos. Ela pode manter-se viva somente cultivando justamente esta natureza paradoxal. 
Citamos aqui apenas dois paradoxos: o estado democrático depende de condições que ele mesmo não pode garantir. Ele não pode interferir no uso da liberdade que oferece, porque, do contrário, ele a obstrui simultaneamente (Böckenfröde 1976, p. 60). No mesmo viés, tem-se o paradoxo entre o princípio da democracia e do Estado de direito: a democracia sem nenhuma limitação pode resultar no fim da liberdade do indivíduo. Por isso, existe o Estado de direito, que protege o indivíduo, mas acaba interferindo na liberdade democrática. Ao longo do nosso estudo, encontraremos ainda outras contradições deste tipo. Isso fará com que as nossas respostas sempre sejam relativistas: a nossa avaliação sobre os processos de democracia direta dependerá sempre do contexto no qual eles estão sendo aplicados.

Além desse problema fundamental da democracia, somos confrontados com outros atritos no que diz respeito aos processos de democracia direta mais especificamente: no âmbito teórico, encontramos regularmente argumentações metodologicamente incoerentes, por exemplo, ao comparar uma visão pessimista dos processos de democracia direta a uma visão otimista das instituições representativas (Lutz, 2006, p. 45). No âmbito empírico, o maior desafio é o número relativamente pequeno de experiências com processos de democracia direta. Esse fato limita as possibilidades de análises quantitativas, ainda mais se considerarmos que os contextos dessas experiências são bem diversificados e dificultam as comparações. Como constata Hug (2009), a interação entre processos de democracia direta e as instituições representativas também foi pouco pesquisada.

\section{II.1. A questão entre o minimalismo e o maximalismo democrático}

As argumentações mais simples contra ou a favor dos processos de democracia direta derivam-se do minimalismo e do maximalismo democrático. No minimalismo, condensa-se a posição de que a democracia é um meio para limitar o poder. A solução para atingir esse fim é permitir a alternação dos detentores do poder por meio de eleições. No outro extremo, encontra-se o maximalismo democrático, no qual a participação direta e contínua dos cidadãos é vista como conditio sine qua non para o funcionamento da democracia. $\mathrm{Na}$ realidade, as duas posições assumem uma relação causal entre as instituições democráticas e os resultados políticos produzidos por elas, e abordam as instituições como um valor em si e não como um meio (Gurza-Lavalle 2011).

No minimalismo democrático, a premissa é: uma democracia é boa enquanto a alternação dos detentores do poder é possível. Neste respeito, Schumpeter (1962) é um dos representantes mais expressivos. Segundo ele, basta a possibilidade da escolha entre duas plataformas partidárias bastante distintas para prevenir uma tirania. Ele defende uma democracia das elites e não se preocupa com as questões de participação popular além das eleições. Aceitando essa premissa, resta pelo menos a pergunta a respeito do intervalo adequado para as eleições. Em torno dessa questão, desenvolve-se um debate desde os Federalistas. Madison escreveu que quanto mais alta a frequência das eleições, mais dependentes os representantes dos cidadãos e mais leais eles seriam às reivindicações populares. Porém, ele não fornece critérios que permitiriam a definição do intervalo em uma situação concreta (Hamilton, Madison \& Jay 1961, p. 295). Amacher e Boyes (1978) mostram que quanto mais longo o período entre eleições, menos os representantes preocupam-se com as reivindicações dos seus eleitores. O problema da fidelidade dos representantes aos representados remete à questão fundamental da representação formulada por 
Pitkin (1967), o representante deve agir como agente do representado, executando diretamente as reivindicações, ou deve agir como mandatário independente do eleitorado, tomando as decisões em função da própria opinião? Aqui não cabe um debate sobre representação, mas é claro que a primeira posição levada ao extremo contradiz a função deliberativa dos órgãos representativos, enquanto a segunda posição levada ao extremo desresponsabiliza o cidadão completamente.

No maximalismo democrático, a premissa é outra: quanto mais uma democracia oferece possibilidades de participação, melhor. A participação é vista como concretização dos princípios fundamentais da democracia: inclusão e igualdade. Todo mundo pode participar da mesma forma na política; não deveria existir uma diferença entre representado e representante. Barber (1984) articula essa visão. Segundo ele, democracia é autogovernança: os cidadãos governam a si mesmos. Não é preciso que os cidadãos intervenham em toda instância, mas eles devem ser incluídos em todas as questões importantes. Para isso, as instituições devem facilitar a participação na definição das agendas, na deliberação, na legislação e na implementação (idem, p. 151). Pateman, outra maximalista, defende ainda que a participação deveria ser estendida, além do âmbito político, para empresas e outras instituições importantes da sociedade (Pateman 1970, p. 104).

Além dessas duas posições contraditórias, existem vários autores com posicionamentos ambíguos. Dahl (1989) incluiu na definição da democracia os direitos de participar, mas esses direitos não incluem necessariamente níveis de participação altos. Podemos observar o mesmo na obra de Bobbio, que vê na democracia um conjunto de regras procedurais para chegar a decisões coletivas. Ele usa o termo participação sem concretizar como o envolvimento do cidadão deveria ocorrer (Bobbio 1987, p. 19). Encontramos uma posição similar em Habermas (1998): nas considerações gerais, ele insiste na importância da participação de todos os atingidos. Mas, quando ele aborda as instituições concretas de um Estado democrático contemporâneo, foca nas deliberações do parlamento e dos tribunais. Em entrevistas, Habermas (2008b) exprime a sua admiração pelos mecanismos de participação direta na Suíça, mas questiona se as instituições suíças abrangem adequadamente as questões políticas da atualidade. Para questões excepcionais como a reunificação da Alemanha ou a Constituição da União Europeia, Habermas (2008a) argumentou publicamente em favor de consultas populares.

O debate entre o minimalismo e o maximalismo democrático é em grande parte teórico e normativo. Ambas as posições são gerais e abstratas e, por isso, não podem ser testadas empiricamente com facilidade. Mesmo assim, podemos formular duas perguntas para ver até que ponto o minimalismo e o maximalismo democrático estão refletidos na realidade.

Primeiro, até que ponto os próprios cidadãos são minimalistas ou maximalistas? Os autores minimalistas partem do pressuposto de que o cidadão tem pouco interesse (e competência) pela política e por isso nem quer uma participação mais ampla. Por sua vez, os autores maximalistas argumentam que o cidadão tem (ou deveria ter) interesse pela participação política. As pesquisas empíricas trazem uma imagem ambivalente: por um lado, existe uma vasta literatura sobre a insatisfação dos cidadãos com as instituições representativas (debate sobre a pós-democracia). Os mesmos cidadãos reivindicam mais mecanismos de participação. Porém, uma análise das taxas de participação em consultas populares mostra que nem todos os cidadãos sentem-se motivados a 
realmente participar na política. Hibbing e Theiss-Morse (2002) demonstram esse ponto de uma maneira bem clara para os Estados Unidos e chegam à conclusão de que, em geral, os cidadãos preferem um sistema democrático "camuflado" (stealth democracy). Com isso, os autores denominam uma configuração institucional normalmente invisível, que vem à tona somente naqueles momentos nos quais os cidadãos realmente querem ser envolvidos no processo político. Bengtsson e Mattila (2009, p. 1045), ao analisarem as atitudes dos finlandeses, chegam a conclusões um pouco mais ambivalentes: segundo eles, cidadãos da Finlândia querem ao mesmo tempo instituições democráticas camufladas e processos de democracia direta. Um outro indicador das preferências dos cidadãos são os níveis de abstenção em eleições e consultas populares. Em geral, a literatura mostra que a participação aumenta com a importância da agenda - nos Estados Unidos, o nível de participação é mais alto nas eleições presidenciais do que nas eleições do midterm. Nesse contexto, Donnovan, Tolbert e Smith (2005) mostram que votações sobre iniciativas populares e referendos representam um estímulo similar, ao comparar níveis de participação em eleições do midterm em estados com e sem processos de democracia direta.

A segunda pergunta que se coloca na comparação entre as posições minimalistas e maximalistas e a realidade empírica é: quais são as escolhas institucionais de fato? Como será demonstrado ao longo deste estudo, existe um leque de diferentes processos de democracia direta, e mesmo um certo tipo, como, por exemplo, o referendo, mostra uma variedade bastante grande. Por isso, a tarefa de contar e comparar países com processos de democracia direta não é fácil. Em um desses esforços, Altman (2011) mostra que, desde 1900, o número de países com processos de democracia direta aumentou consideravelmente. No mesmo período, cresceu ainda mais o uso desses mecanismos (idem, p. 65). Não existem estudos que explicam os motivos pelos quais certos países incluem processos de democracia direta no seu arranjo institucional; Altman mostra que países democráticos usam processos de democracia direta mais do que países híbridos e autocráticos (idem, p. 62, p. 81). Ewert (2007), ao analisar países do Leste europeu, formulou a hipótese de que a introdução de processos de democracia direta é um fenômeno endógeno no que se refere à forma como um país democratiza-se e consegue autonomia para influenciar a adoção de mecanismos de democracia direta.

Em suma, podemos concluir que, de um ponto de vista teórico, tanto a posição minimalista quanto a maximalista contêm contradições normativas e não podem ser encontradas na realidade. Os próprios cidadãos demonstram um comportamento ambivalente: por um lado, tendem a reivindicar direitos à participação, mas nem sempre aproveitam deles.

\section{II.2. A concorrência entre maioria e minoria}

Desde Aristóteles, uma série de autores alega que processos de democracia direta favorecem uma tirania - da maioria ou da minoria. Em qualquer sistema democrático, coloca-se a pergunta fundamental sobre a maneira como as maiorias e minorias constituem-se e como o confronto entre elas é resolvido. As escolhas institucionais têm uma grande influência sobre o comportamento dos atores e resultados políticos, como mostram, por exemplo, estudos que comparam eleições nos modos majoritários ou proporcionais (Dow 2001; Grofman 2004). A concorrência entre minoria e maioria faz parte do regime democrático. Instituições como o Estado de Direito e os direitos humanos podem ameni- 
zar essa tensão. A questão da concorrência entre maioria e minoria, no contexto dos processos de democracia direta, será discutida, em primeiro lugar, sob o ângulo da maioria.

O argumento da tirania da maioria é simples: uma vez que a maioria constitui-se, ela pode oprimir a minoria. Ao visitar a jovem democracia dos Estados Unidos, Alexis de Toqueville chegou a essa conclusão. Bell acha que foi o medo da tirania da maioria que motivou os founding fathers a não incluir processos de democracia direta na Constituição americana (1978).

Do ponto de vista teórico, esses riscos são óbvios. Porém, os estudos empíricos não confirmam tão claramente a hipótese da tirania da maioria. Naturalmente, é fácil citar casos nos quais a maioria optou por deixar a minoria em desvantagem, por exemplo, na votação sobre os direitos políticos das cidadãs suíças, na qual os cidadãos suíços optaram, em 1959, por não atribuir o direito ao voto às mulheres; em 1971, essa decisão foi revertida em uma segunda consulta popular. Mas, considerando um número representativo de consultas populares, em vez de somente alguns casos extremos, verifica-se que não se formam por definição maiorias opressoras e estáveis em processos de democracia direta. Nesse contexto, Kobach (1993) tira uma conclusão oposta quando analisa o referendo suíço, no qual a população pode vetar decisões tomadas pelo parlamento. $\mathrm{O}$ pedido por um referendo pode ser feito por um grupo relativamente pequeno, por meio de um abaixo-assinado. A simples ameaça de um referendo regularmente leva a maioria a aceitar reivindicações da minoria, justamente para evitar um referendo. Nesse sentido, podemos dizer que processos de democracia não levam à uma tirania da maioria, mas sim à tirania do consenso (Kobach, 1993; Gerber, 1999). Uma variação do argumento da tirania da maioria consiste em alegar que os processos de democracia favorecem o status quo e com isso as forças conservadoras. Frey e Goette (1998), ao analisar o caso da Suíça, chegam à conclusão de que somente $23 \%$ das propostas em processos de democracia são conservadoras e questionam a hipótese do conservadorismo inerente. Donovan e Bowler (1998), que estudam o caso da Califórnia, concluem que $18 \%$ dos resultados de processos de democracia direta são antiminoritários. Eles observam que o suporte para minorias aumenta com o tamanho do distrito eleitoral (idem, p. 1022). Haider-Markel, Querze e Lindaman (2011), em uma tentativa de replicar os resultados de Donovan e Bowler no campo dos direitos dos homossexuais, chegam a uma conclusão menos favorável: ao analisar 143 consultas populares nos níveis municipal e estadual nos Estados Unidos, eles constataram que 71\% das propostas foram rejeitadas, em desvantagem das minorias homossexuais. Hajnal, Gerber e Louch (2011) verificam, ao analisar o caso da Califórnia, que minorias étnicas regularmente ganham em consultas populares, já que elas compartilham os mesmos interesses como da maioria branca. Somente quando os direitos das minorias étnicas estão em pauta, o risco de perder a votação é maior. Matsusaka, ao analisar a situação geral dos Estados Unidos, chega a uma conclusão similar: ele não encontra nenhuma evidência de que as minorias são mais oprimidas em processos de democracia direta do que pelos parlamentos (Matsusaka 2011, p. 22). Altman, ao estudar processos de democracia direta no mundo inteiro, também não consegue identificar provas com impactos negativos na diversidade social (Altman 2011, p. 85).

Em suma, os estudos empíricos não negam o perigo de uma tirania da maioria, tampouco confirmam que esse risco realiza-se constantemente. Ademais, existe um mecanismo que permite remediar o risco da tirania da maioria: quóruns, que exigem maiorias qualificadas para a aprovação de uma proposta. A 
definição do quórum pode basear-se na taxa de aprovação ou na taxa de participação. O objetivo é sempre o mesmo: evitar decisões por maiorias aleatórias (Jung, O. 2010). É interessante notar que quóruns parecem reduzir a participação em votações: Aguiar-Conraria e Magalhães (2010) mostram, em uma análise sobre todos os referendos feitos em países da União Europeia entre 1970 e 2007, que quóruns aumentam a abstenção em mais de $10 \%$.

A hipótese da tirania da minoria é mais recente e baseia-se em dois argumentos. O primeiro vem da escolha racional que alega que minorias podem manipular a agenda de votações, para que seus interesses prevaleçam. É possível mostrar esse tipo de ciclos em modelos teóricos (Arrow 1963; Cunningham 2002; Hug 2004; Abbink 2006); porém, não existe um caso empírico que prove a ocorrência de ciclos em votações populares (Altman 2011, p. 48). A inexistência de ciclos no contexto de processos de democracia direta não é surpreendente, afinal, esses processos são lentos e dificilmente controláveis; seria muito mais fácil manipular a agenda em um parlamento. Uma variação desse argumento é que minorias podem impor a inclusão de reivindicações que a maioria normalmente não aceitaria, mas pode aprovar para que o pacote todo seja aprovado. Para evitar este tipo de compromisso forçado, a legislação dos processos de democracia direta pode impor que as consultas populares sempre devem focar em uma só questão. A Suíça conhece essa regra da unidade da matéria (Art. 194 II e III da Constituição suíça); mesmo assim, nem sempre é fácil formular a proposta sem interferir nesse princípio. Kirchgässner (2008) mostra que o eleitorado suíço regularmente rejeita propostas de pacotes, justamente porque não aceita ser manipulado.

$\mathrm{O}$ segundo argumento alega que minorias com muitos recursos financeiros podem comprar resultados a seu favor. Essa posição baseia-se principalmente nas experiências dos Estados Unidos, nos quais os orçamentos das campanhas de referendos e iniciativas populares aumentaram consideravelmente. Lá, a legislação prevê que, para a iniciação de um processo de democracia direta, exista um número de assinaturas relativamente alto em um período curto. Com base nessa exigência, criou-se uma indústria especializada em colecionar assinaturas; por exemplo, no estado da Califórnia, é possível colocar qualquer questão na agenda política com um investimento de aproximadamente um milhão de dólares (Broder 2000, p. 243; Mathews 2006). Porém, vários autores mostraram que é difícil comprar a aprovação de uma proposta com dinheiro; este compra muito mais facilmente a rejeição de uma proposta do que a aprovação (Gerber 1999; Matsusaka 2011, p. 22). Na conclusão de uma coleção de estudos sobre a regulamentação de campanhas de consultas populares, Gilland Lutz e Hug (2010) constatam que dinheiro certamente tem um papel importante, mas que a ciência ainda não conseguiu desvendar claramente esses mecanismos.

Em suma, assim como na questão do perigo da tirania da maioria, concluise que existem casos empíricos, nos quais a minoria conseguiu "comprar" um resultado na base dos fartos recursos, mas não se trata de um fenômeno dominante.

\section{II.3. A concorrência entre as instituições representativas e os processos de democracia direta}

Até agora, nosso debate voltou-se aos problemas gerais da democracia. Ao abordar a concorrência entre as instituições representativas e os processos de democracia direta, levantamos a questão central. Na introdução, formulamos a 
hipótese de que os processos de democracia direta são complementares e não substituem as instituições representativas; nesta seção, analisaremos as posições teóricas e os resultados empíricos a respeito. As instituições representativas e os processos de democracia direta realmente complementam-se? Existem também áreas de conflito?

Segundo Broder (2000), o conflito entre processos de democracia direta e o governo representativo é total; na visão dele, as iniciativas populares estão destruindo as instituições democráticas dos Estados Unidos. É um fato que alguns estados norte-americanos encontram-se em situações políticas complicadas e que certas votações populares contribuíram para isso; mas seria um exagero responsabilizar os processos de democracia direta pela totalidade dos problemas. Altman (2011 p. 42) concorda em parte com Broder quando ele alega que processos de democracia direta fragilizam a posição dos representantes eleitos, afinal, eles não detêm mais exclusivamente o poder Legislativo.

A constatação de Altman parece óbvia; porém, uma análise mais aprofundada mostra que os efeitos dos processos de democracia direta não vão em uma só direção. Por um lado, é claro que, uma vez que os representantes eleitos não podem mais decidir sozinhos, o poder deles torna-se mais limitado. Por outro lado, consultas populares provocam dois efeitos positivos para os representantes: em primeiro lugar, mesmo em um regime que permite o veto popular das decisões parlamentares, a grande maioria das decisões não é vetada; por isso, todas as políticas não vetadas podem ser consideradas implicitamente aprovadas pelos cidadãos. Em segundo lugar, as consultas populares, que ocorrem mais regularmente que as eleições, fornecem aos parlamentares orientações mais específicas sobre as preferências dos cidadãos que resultados eleitorais. Assim, os eleitos podem posicionar-se de uma maneira mais calibrada diante dos cidadãos. Isso aumenta suas chances de serem reeleitos.

A questão mais geral que se coloca então é: qual é a ligação entre o eleitor e o eleito, entre o representado e o representante? Como primeiro intuito, podemos recorrer ao conceito de principal e agente (Lapuente 2011, p. 2127) que pretende descrever e explicar as dinâmicas entre um principal, que contrata um agente para executar uma tarefa em troca de um preço. O pressuposto básico é que existem duas assimetrias entre o principal e o agente: a primeira diz respeito às preferências: o principal procura a boa execução da tarefa, enquanto o agente maximiza o preço que ele pode cobrar do principal. A segunda assimetria diz respeito às informações: o agente geralmente dispõe de mais informações do que o principal e tenta aproveitar-se dessa vantagem. Existem inúmeras propostas para solucionar esses dilemas, sendo a mais simples estabelecer o preço em função dos resultados obtidos pelo agente.

Aplicando esse conceito ao contexto político, à primeira vista, o representado aparece como principal e o representante como agente. Porém, ao contrário de casos usuais de principal e agente, o cidadão que está delegando o seu poder ao agente político encontra-se de repente em uma posição subordinada, já que o agente político assume o papel do legislador e representante do poder público. Nesse sentido, no jogo político existe uma inversão dos papéis. Por causa dessa inversão paradoxal, o conceito de principal e agente clássico não pode ser aplicado diretamente na análise da ligação entre eleitor e eleito.

Pitkin (1967), no seu trabalho seminal sobre a questão da representação, identificou este problema relativo à controvérsia entre mandato versus independência. $\mathrm{O}$ eleito pode conceber o seu papel como delegado, com uma margem de julgamento relativamente grande ou como um mandatário que 
simplesmente transmite as preferências dos seus eleitores (idem, p. 145). Mas, independentemente da forma como o eleito interpreta o seu papel, mais cedo ou mais tarde, ele tem que justificar os seus atos aos eleitores. Estes reelegerão o mesmo ou preferirão votar em outro candidato; trata-se do mecanismo de accountability vertical ou eleitoral. A questão é se o mecanismo da reeleição é suficiente para alinhar o representante ao representado ou se outros mecanismos são necessários para garantir a congruência entre as preferências dos eleitores e os atos dos eleitos.

Existem vários estudos que mostram que sistemas puramente representativos produzem regularmente distorções entre a vontade popular e a política promovida pelos eleitos: ao analisar o Partido Socialista da Espanha nas campanhas entre 1982 e 1996, Maravall (1999) mostra que esse partido manipulou os eleitores para chegar ao poder e manter-se. Matsusaka (2011, p. 21) mostra que, nos Estados Unidos, quase todos os estados com a iniciativa popular possuem limites de reelegibilidade, enquanto que quase todos os estados sem tal mecanismo permitem reeleições ilimitadas; ele interpreta esse fato como prova de que processos de democracia direta permitem ao eleitor impor os seus interesses contra os eleitos. Outros autores confirmam essa observação, em particular em casos de países com estruturas pouco consolidadas, como é o caso na América Latina (Altman 2011, p. 34). Pettit (2003) faz a constatação de que eleitos, uma vez no cargo, tendem a esquecer as promessas feitas na campanha e preocupam-se apenas com os próprios interesses. Por isso, Setälä (1999) argumenta que os processos de democracia direta podem servir como instituições de correção. Altman toma uma posição similar ao caracterizar processos de democracia direta como válvulas de segurança para momentos nos quais o sistema representativo não reflete a vontade popular (Altman 2011, p. 43, p. 59). Em um estudo histórico, Tolbert (2003) mostra que, nos Estados Unidos, em momentos de importantes mudanças sociais e econômicas, as instituições representativas foram modificadas por meio dos processos de democracia direta.

Em termos mais gerais, Möckli (1994) classifica as funções de processos de democracia direta em três fases: (i) a função input consiste na possibilidade de o cidadão colocar questões na pauta política, independente do apoio do seu representante. (ii) A função de processamento refere-se à ampliação do número de pessoas envolvidas na deliberação de uma questão política. (iii) Já a função output diz respeito às decisões políticas com uma legitimidade maior que aquela conferida a um parlamento, visto que todos os cidadãos podem dar o aval, e não somente a elite política.

O postulado da complementaridade, porém, não deve enganar: a introdução de processos de democracia direta afeta o jogo político de uma maneira fundamental: em todas as questões importantes existe o perigo de (ou a obrigatoriedade de) uma consulta popular (Grotz 2009, p. 291; Jung 2001). Para que os representantes não comprem constantemente briga com os representados, aqueles têm que antecipar reivindicações populares e até minoritárias, já que mesmo grupos pequenos podem provocar iniciativas e ou vetos populares (Neidhart 1970; Vatter 1997; 2002; Jung 2001). Nem sempre, as iniciativas e os vetos populares têm o êxito desejado pelos iniciadores, mas a retardação da decisão final já pode trazer custos políticos altos. O deslocamento do poder reflete-se também no relacionamento entre representado e representante: a inversão dos papéis de principal e agente, mencionada anteriormente, é - pelo menos parcialmente - revertida. Isso deve mostrar-se também nos modos de comunicação: os representantes precisam explicar as suas políticas constante- 
mente aos eleitores e, talvez ainda mais importante, devem prestar atenção no que estes dizem, já que eles podem tentar reverter as decisões tomadas pelos representantes (Bowler, Donovan \& Karp 2007).

Porém, seria um exagero postular uma oposição total entre representados e representantes. Em primeiro lugar, os representantes continuam tomando a maioria das decisões e, por isso, exercem também maior influência na política, como mostra, por exemplo, Serdült (2007) para a Suíça. Em segundo lugar, os representantes e seus partidos têm uma grande influência também nos processos de democracia direta. A ideia de que processos de democracia derivam unicamente do apoio popular não corresponde com a realidade. $\mathrm{O}$ apoio ideológico, logístico e financeiro dos partidos e de outros grupos, tradicionalmente vinculados aos representantes, é fundamental para o êxito de processos de democracia direta (Bowler \& Hanneman 2006, p. 566; Altman 2011, p. 49). Regularmente, são mesmo os partidos que começam iniciativas ou vetos populares, justamente para solucionar conflitos travados nos órgãos representativos (Mendelsohn \& Parkin 2001, p. 7; Breue 2008, p. 20).

A mescla entre representado e representante, entre o eleito e o eleitor fica ainda mais acentuada em situações nas quais as consultas populares não acontecem com frequência. Nessas situações, consultas populares frequentemente viram eleições de segundo grau (second order elections). Apesar do fato de essas consultas populares tratarem de questões específicas, elas tornam-se plebiscitos sobre os eleitos. Em vez de opinar sobre a questão específica, a população tende a passar um veredicto sobre o governo (Franklin, Eijk \& Marsh 1995; Svensson 2002; Hobolt 2008). Hug (2002) mostra que, quando o resultado de um referendo é somente consultivo, os eleitores tendem a votar contra o governo. Essas considerações mostram que a introdução de processos de democracia direta puramente consultivos pode criar mais problemas do que resolver. Tanto os eleitores como os representantes e a mídia precisam habituar-se com os processos de democracia direta para saber usá-los e interpretá-los corretamente. Noutro caso, os resultados de consultas populares tendem a ser aleatórios e levam a frustrações de todos os envolvidos (Leduc 2003, p. 82). Mesmo quando o uso de processos de democracia direta é frequente, ele tende a criar um mal-estar político constante, já que os conflitos políticos não se restringem ao parlamento, mas, sim, são resolvidos com a participação de todos os eleitores (Dyck 2009, p. 546). Dyck observa ainda que a confiança no governo tende a ser menor porque, nem sempre, as propostas aprovadas pelos cidadãos podem ser implementadas.

Na questão da concorrência entre as instituições representativas e os processos de democracia direta, Gerber (2011) adota uma perspectiva alternativa: com estudos de caso, ela mostra que diferentes contextos institucionais favorecem diferentes forças políticas e, com isso, diferentes resultados. Quando se trata de questões que recebem um vasto apoio da população (no exemplo dela, a taxação de cigarros), a aprovação é mais fácil em consultas populares. Porém, quando interesses de importantes contribuintes para as campanhas eleitorais estão em jogo, o caminho por meio das instituições representativas é mais promissor.

Outro ponto é levantado por Gerber, Lupia e McCubbins (2011) ao analisar a fase de implementação de decisões feitas em processos de democracia direta: eles constatam amplas possibilidades do poder Legislativo, do Executivo e da administração de obstruir as intenções expressas nas consultas populares. Ferraiolo (2011) conclui, a partir de entrevistas com líderes do estado de Maine, 
que os legisladores e a burocracia são mais favoráveis aos processos de democracia direta que Gerber, Lupia e McCubbins (2011) supunham.

Em suma, podemos constatar que a introdução de processos de democracia direta pode tornar um sistema democrático representativo mais legítimo. Porém, a legitimidade adicional tem um preço: o processo político torna-se mais complexo. Somente quando os representantes enfrentam essa complexidade abertamente, pode-se esperar resultados positivos; caso contrário, o jogo político torna-se mais confuso e, com isso, menos democrático.

\section{II.4. A questão da competência dos cidadãos}

Enquanto a questão da concorrência ou complementaridade entre os processos de democracia direta e as instituições refere-se à dimensão institucional, temos igualmente que considerar o fator humano. Nesse contexto são inúmeros os autores que alegam que os cidadãos são incapazes de decidir questões políticas específicas por eles mesmos. Sartori defende que "a democracia direta afundará imediatamente nas rochas da incompetência cognitiva" (Sartori 1987, p. 120). Campbell et al. (1960) e Budge (1996) defendem posições similares. Para Suski (1993), processos de democracia são incontroláveis e imprevisíveis. Em contraste aos autores pessimistas, outros argumentam que a participação em processos de democracia direta ajuda o cidadão a tornar-se politicamente competente (Smith 2002; Batt 2007, p. 131; Rauschenbach 2010; 2012).

Aqueles autores que ao mesmo tempo são céticos sobre os processos de democracia direta, mas defendem as instituições representativas, são contraditórios: como os cidadãos podem, por um lado, ser competentes nas eleições e, por outro, incompetentes nas consultas populares? Matsusaka (2011, p. 20) argumenta que eleitores correm mais riscos de errar em eleições do que em consultas populares, porque eleições envolvem sempre um leque abrangente de dimensões, enquanto consultas populares focam em questões mais concretas.

Estudos empíricos mostram que os cidadãos aplicam estratégias iguais na tomada de decisões, seja em eleições, seja em consultas populares. No fundo, o problema é o mesmo: conciliar as informações limitadas com os próprios interesses. Bowler e Donovan (1998) observam que cidadãos votam de uma maneira previsível, levando em conta a ideologia e os próprios interesses. Em situações nas quais os cidadãos não têm informações suficientes para tomar uma decisão, tendem a votar contra a mudança. Assim, eles têm um comportamento bem similar ao dos representantes (Bowler \& Donovan 1998, p. 168). No fundo, os cidadãos seguem uma estratégia heurística que se baseia tanto nas informações disponíveis como também nas recomendações de pessoas e instituições confiáveis. Desse modo, os cidadãos são capazes de opinar corretamente conforme os próprios interesses, sem necessariamente conhecer e entender todos os detalhes técnicos de uma proposta. LeDuc (2003), em uma análise sobre referendos em várias partes do mundo, caracteriza três tipos de formação de opinião. O primeiro refere-se a questões que não envolvem posições ideológicas e partidárias fortes: nesses casos, a formação de opiniões é bastante volátil e o resultado pouco previsível. O segundo tipo trata casos nos quais é possível, durante a campanha, introduzir novos argumentos que literalmente revertam as posições. O terceiro tipo refere-se a consultas populares sobre temas que já são do ponto de vista ideológico e/ou partidário, claramente 
estruturados e para os quais existem indicadores heurísticos óbvios. Nesse último caso, é difícil mudar as posições dos cidadãos.

Em vista da importância das estratégias heurísticas, Matsusaka questiona a relevância de pesquisas que avaliam a competência dos cidadãos na base do conhecimento técnico do funcionamento do Estado ou dos nomes dos atualmente eleitos; em muitos casos, esse tipo de informação não é crucial para participar em consultas populares (Matsusaka 2011, p. 19). Lupia (1994) e Lupia e McCubbins (1998) confirmam esse achado. Kahn e Matsusaka (1997) mostram que os eleitores são capazes de identificar corretamente o impacto econômico de iniciativas populares e votam em função disso. Christin, Hug e Sciarini (2002) concluíram, a partir de um estudo sobre referendos suíços entre 1981 e 1990, que cidadãos mal-informados têm uma tendência a optar pelo não, para preservar o status quo. Segundo os mesmos autores, o apoio em estratégias heurísticas depende das circunstâncias, um achado confirmado por LeDuc (2003). Schuck e de Vreese (2011), ao analisarem o referendo holandês sobre a Constituição Europeia, mostram que cidadãos que leram tabloides ficaram com medo da possível aprovação da Constituição e rejeitaram o referendo.

A capacidade dos cidadãos para processar informação é limitada: Lutz (2007) mostra que quanto mais questões estão em pauta, pior os cidadãos estão informados sobre cada assunto; esse achado é confirmado por Selb (2008, p. 33). Meredith (2009) observa também que eleições que acontecem simultaneamente com uma consulta popular podem afetar negativamente o grau de informação dos cidadãos.

Anderson e Goodyear-Grant (2010) analisaram a autoavaliação dos cidadãos canadenses ao medir o apoio dos cidadãos mais bem informados para referendos em geral. A literatura parte da hipótese de que quanto mais alto o nível educacional, menor o apoio aos processos de democracia direta. Enquanto os autores confirmam essa hipótese, eles acreditam que o motivo não se baseia na desconfiança na competência dos outros cidadãos, mas, sim, na confiança da competência do governo e no medo do desrespeito das minorias em consultas populares. Porém, os autores insistem que a pesquisa foi feita logo após alguns referendos complexos que podem ter influenciado de uma maneira exagerada a autoavaliação dos canadenses.

Os que questionam a competência do cidadão referem-se não somente à pressuposta incapacidade de informar-se e chegar a conclusões corretas, mas também à inclinação de se deixar manipular por populistas. Esse argumento vai em paralelo com o argumento de que processos de democracia direta podem ser facilmente dominados por minorias. O argumento da manipulação é delicado, porque a delimitação entre informação e manipulação não é fácil, tampouco é fácil determinar se o voto de um cidadão realmente corresponde com os seus próprios interesses ou se ele foi induzido pela manipulação.

O perigo da manipulação não pode ser negado facilmente. Em particular nos Estados Unidos, são investidos valores alucinantes em campanhas que favorecem ou combatem referendos e iniciativas populares. As campanhas aproveitam-se de todos os truques de marketing para garantir o resultado desejado. Altman observa, porém, que a legislação americana trata eleições e consultas populares de maneiras bem distintas: enquanto a arrecadação e o uso de dinheiro em eleições são altamente regulados, esse não é o caso dos processos de democracia direta (Altman 2011, p. 54). Então surge uma pergunta: o potencial de manipulação é inerente aos processos de democracia direta ou simplesmente fruto de uma lacuna legislativa? Ao contrário dos Estados Unidos, a 
Suíça conhece uma legislação severa a respeito da propaganda política: qualquer propaganda política no rádio e na televisão é proibida. Essa regra reduz de maneira considerável a pressão financeira sobre as campanhas, já que o rádio e a televisão são os veículos de comunicação mais caros e, por não serem meios escritos, são também os mais emotivos. O poder da televisão é questionado por Bowler e Donovan (2002). Em um estudo sobre o estado de Washington, eles chegam à conclusão que campanhas na televisão não têm grande influência na opinião dos cidadãos. No melhor dos casos, elas alertam sobre a votação e motivam a procura de informação em outras fontes.

No contexto do debate da competência do cidadão, surge a questão do voto obrigatório. $\mathrm{O}$ argumento clássico em favor do voto obrigatório diz que ele garante que aqueles cidadãos que, sem obrigatoriedade, não votariam também sejam representados. Além disso, supõe-se que o voto obrigatório tem um efeito educacional e incentiva futuramente todos os cidadãos a participar na política, mesmo sem obrigação. Higley e McAllister (2002) mostram em um estudo sobre o referendo constitucional australiano de 1999 que o voto obrigatório realmente fez com que cidadãos, que não tinham a intenção, sentissem-se forçados a votar. Porém, os autores mostram também que, em consequência, a competência média dos cidadãos ficou reduzida, por que cidadãos que não se sentiam competentes para participar na consulta popular votavam de qualquer forma, simplesmente para evitar uma multa. Pelo menos no caso da Austrália, o voto obrigatório produziu então um resultado ambivalente. No contexto do presente estudo, não foi encontrada pesquisa que comprove empiricamente os efeitos educacionais do voto obrigatório.

Do ponto de vista normativo, seria desejável evitar a obrigatoriedade do voto sem arriscar níveis altos de abstenção. Parece que processos de democracia podem contribuir para isso: Tolbert e Smith (2005) mostram em uma análise das eleições americanas entre 1980 e 2002 que a abstenção é sistematicamente menor em eleições que combinam consultas populares.

Já mencionamos a contradição de atribuir ao cidadão a competência de saber eleger o seu representante e ao mesmo tempo a incompetência de participar em processos de democracia direta. Além dessa contradição, surge outra questão, a incompetência é inalterável ou o cidadão pode superá-la? Em caso afirmativo, de que maneira? Embasados pela psicologia do desenvolvimento cognitivo, podemos argumentar que o cidadão pode, de fato, adquirir as competências para participar ativamente nas decisões políticas. Desse ponto de vista, os processos de democracia mostram-se, na verdade, ser ferramentas poderosas de treinamento e aprendizado (Rauschenbach 2010; 2012). Smith (2002), ao analisar dados derivados das eleições do Senado norte-americano de 1992, chega à seguinte conclusão: cidadãos que participam regularmente em processos de democracia direta têm conhecimentos mais amplos sobre a política em comparação com os que ou não participam ou não têm acesso aos mecanismos da democracia direta. Batt (2007) argumenta na mesma direção e destaca a importância da educação cívica, para que os cidadãos realmente saibam aproveitar as oportunidades da democracia direta. Além das instituições, da vontade de usá-las e da competência cívica, são necessárias também informações que permitam ao cidadão tomar uma decisão adequada. Boehmke e Bowen (2010) descubriram que, nos estados norte-americanos que permitem processos de democracia direta, surgem mais associações que defendem interesses específicos e mais cidadãos participam nesses grupos. Podemos assumir que o engajamento cívico resulta em competências mais elevadas daqueles cidadãos. No contexto do referendo sobre o acordo constitucional europeu na 
Holanda, Neijens e de Vreese (2009) mostram que a informação estruturada em um questionário é mais informativa ao cidadão que as matérias tradicionais.

Em suma, podemos concluir que a visão de que o cidadão é profundamente incompetente para participar em decisões políticas específicas não pode ser sustentada nem teórica nem empiricamente. Por outro lado, seria demasiadamente idealista argumentar que o cidadão dispõe, por natureza, de todas as competências necessárias para participar adequadamente em processos de democracia direta. O cidadão precisa ser educado e treinado para poder exercer os seus direitos democráticos. Ele depende de informações e indicadores heurísticos de fontes que não são sistematicamente manipuladas. Isso requer uma legislação que limita excessos nas campanhas.

\section{II.5. A questão do tamanho do eleitorado}

Na seção anterior mostramos que a competência dos cidadãos depende de uma série de fatores, como o fornecimento de informações e indicadores heurísticos de fontes confiáveis. Há autores que argumentam que a partir de certo tamanho de eleitorado, essas dificuldades não podem mais ser sanadas. Por isso, alegam que processos de democracia direta deveriam ser limitados ao nível local. Weber (1985, p. 546) e Schumpeter (1962, p. 267) argumentam que processos de democracia direta devem ser aplicados somente em questões simples e administrativas e em contextos de populações homogêneas. Nem sempre fica claro se esses autores rejeitam consultas populares por causa da dificuldade do envolvimento de grandes números de pessoas em deliberações, por supostos problemas logísticos ou pela suposta incompetência dos cidadãos

O envolvimento pessoal é possível somente em grupos muito pequenos; desse ponto de vista, não faz uma diferença substancial se o eleitorado é de 10 000, 100000 ou de 1000000 de cidadãos. O que é muito mais relevante para a qualidade das deliberações é como o sistema das mídias está estruturado e como o Estado informa os cidadãos. Problemas de logística - e com o crescente uso de meios eletrônicos - de confidencialidade não podem ser negados. Porém, existem soluções tecnológicas que permitem a execução de consultas populares de uma maneira confiável. A seguinte tabela lista os maiores eleitorados que já participaram em consultas populares; nessa categoria, o Brasil é campeão do mundo.

Tabela 1 - Os maiores eleitorados em consultas populares

\begin{tabular}{lcccc}
\hline País & $\begin{array}{c}\text { Eleitorado (mi- } \\
\text { lhões de cida- } \\
\text { dãos) }\end{array}$ & Assunto da consulta popular & Tipo de processo de democra- & $\begin{array}{c}\text { Ano da } \\
\text { consulta } \\
\text { popular }\end{array}$ \\
\hline Brasil & 122 & $\begin{array}{c}\text { Referendo sobre a proibição da comercialização } \\
\text { de armas de fogo e munição }\end{array}$ & Plebiscito parlamentar & 2005 \\
Rússia & 106 & Nova Constituição & Plebiscito presidencial & 1993 \\
França & 41 & Constituição da União Europeia & Referendo presidencial & 2005 \\
Espanha & 34 & Constituição da União Europeia & Plebiscito parlamentar & 2005 \\
Polônia & 30 & Adesão à União Europeia & Plebiscito parlamentar & 2003 \\
Colômbia & 25 & 15 assuntos diferentes & Plebiscito parlamentar & 2003 \\
Venezuela & 16 & Reforma constitucional & Referendo constitucional obri- & 2007 \\
& & Proclamação da República & Referendo constitucional obri- & 1999 \\
Austrália & 16 & & \multicolumn{2}{c}{ gatório } \\
\hline
\end{tabular}


Como já constatamos no debate sobre a concorrência entre instituições representativas e processos de democracia direta, defensores da posição contra consultas populares com eleitorados grandes arriscam uma inconsequência, já que, em muitos casos, o mesmo eleitorado elege também diretamente o Presidente da República; nesse caso, os desafios na deliberação e logística são os mesmos.

Em suma, podemos concluir que o tamanho do eleitorado pode representar desafios substanciais na execução de consultas populares. Porém, esses desafios não são inerentes às consultas populares; eles surgem também em outros contextos institucionais das sociedades contemporâneas. Felizmente existem meios técnicos que permitem organizar a logística. A qualidade da deliberação depende muito menos do tamanho do eleitorado e muito mais das características socioeconômicas da população, da regulamentação das campanhas e de como as autoridades atuam.

\section{II.6. A questão dos efeitos colaterais dos processos de democracia direta}

A função principal de processos de democracia direta é a produção de decisões políticas com alta legitimidade. Mas processos tão complexos e impactantes como os da democracia direta não se limitam a este efeito. Surge então a questão sobre os efeitos colaterais dos processos de democracia direta, que evidentemente podem ser de natureza positiva ou negativa. Möckli (1994) fornece um detalhamento dessa função: no nível macro, ele fala da estabilização, legitimação e inovação. Processos de democracia direta estabilizam o sistema político porque aproximam a periferia ao centro político, já que decisões tomadas pelo cidadão não podem ser tão facilmente invalidadas por decisões parlamentares. A legitimação deriva do maior número de envolvidos na decisão final. Processos de democracia direta podem ser inovadores porque permitem o surgimento de ideias que, em um sistema puramente representativo, não poderiam ou não seriam apresentadas. No nível intermediário, Möckli menciona a resolução de conflitos e a criação de aceitação; processos de democracia podem funcionar como válvula de escape. Com o envolvimento do maior número de pessoas possível, a aceitação de decisões é mais alta que no caso de aprovações parlamentares. No nível micro, Möckli inclui a socialização, no sentido de que a participação política individual permite um aprendizado e a integração do indivíduo com e no seu contexto político.

Nos últimos anos, foram avaliados esses e outros efeitos dos processos de democracia direta, dos quais os principais serão discutidos abaixo. Trataremos, em primeiro lugar, o efeito sobre a atividade econômica, seguido pelos efeitos no processo político e na eficiência da máquina pública. Depois será abordada outra questão: processos de democracia direta fazem com que os cidadãos soneguem menos impostos?

Feld e Kirchgässner $(2001 ; 2007)$ argumentam que processos de democracia direta têm um impacto favorável à situação macroeconômica de um país, demonstrando que esses instrumentos reduzem as dívidas do Estado e aumentam a eficácia das administrações públicas. Blomberg, Hess e Weerapana (2004) chegam a conclusões similares ao analisar a força econômica dos estados dos EUA entre 1969-1986: estados que permitiam iniciativas populares cresceram mais rapidamente e mostraram rendas per capita mais altas que os demais. Altman (2011, p. 86), em uma análise mundial, não chega a uma conclusão clara; segundo ele, metodologicamente (ainda) não é possível compro- 
var se processos de democracia direta favorecem o crescimento econômico ou não; por enquanto, não existem dados suficientes que permitam um controle adequado de outros fatores, que podem igualmente influenciar o desenvolvimento econômico.

Já mostramos, ao debater a concorrência entre instituições representativas e processos de democracia, que os últimos alteram fundamentalmente o processo político. Em seguida, será abordada a questão sobre em que medida processos de democracia direta afetam a eficiência política. Nesse contexto, surge regularmente a crítica que eles prolongam e freiam a tomada de decisões. Altman (idem, p. 50) mostra que isso ocorre de fato, mas pergunta, ao mesmo tempo, até que ponto isso representa um problema? Afinal, a mesma crítica pode ser feita às segundas câmaras de parlamentos, que igualmente complicam o processo legislativo. A vantagem desses "freios" é que eles produzem decisões mais legítimas; o preço é uma certa lentidão. Porém, no longo prazo, essa lentidão pode ser nivelada, já que decisões mais legítimas precisam ser mudadas menos rapidamente.

Voltando aos argumentos apresentados a respeito da concorrência entre instituições representativas e processos de democracia direta, pode ser mencionado que, nem sempre, os representantes respeitam os interesses dos cidadãos e, por isso, promovem políticas não desejadas. Processos de democracia direta facilitam a correção desses desvios e permitem uma eficiência política mais alta (Blume, Müller \& Voigt 2009, p. 435). A correção pode ser feita mais facilmente em processos de democracia direta, porque neles questões específicas são abordadas, em vez de programas gerais, apresentados pelos candidatos em eleições. A separação das questões evita também acordos que são meros compromissos, sem correspondência com a solução ideal (idem, p. 438).

O argumento da informação assimétrica contraria a afirmação de que os representados sabem melhor que os representantes quais são os seus interesses. Em questões altamente técnicas, esse argumento certamente é válido. Mas, em muitos casos, processos de democracia direta não visam questões técnicas, mas, sim, questões de valores e preferências individuais. Nesses casos, o cidadão não tem nenhuma desvantagem informacional e sabe tomar a decisão (Matsusaka 2005, p. 193).

Coloca-se então a pergunta, quais são os efeitos dos processos de democracia direta sobre a máquina pública? Em um estudo pioneiro, Pommerehne (1983) mostrou que os custos para a coleta do lixo eram menores naqueles municípios suíços que conheciam processos de democracia direta. Desde então, várias pesquisas abordaram esse tema e chegaram quase sempre à mesma conclusão: a existência e o uso de processos de democracia direta têm efeitos positivos na máquina pública. Matsusaka (2004) analisou os efeitos do direito à iniciativa popular sob a política fiscal e observou que estados que permitem processos de democracia direta arrecadam menos impostos e têm também gastos menores que estados com apenas instituições representativas. Feld e Kirchgässner (2001) fazem para a Suíça a mesma observação: em cantões onde existe o referendo obrigatório, a arrecadação é $7 \%$ e os gastos $11 \%$ menor que o dos cantões sem referendo obrigatório. Freitag e Vatter (2006) replicam esse achado. Wagschal (2011) confirma esse resultado em uma comparação entre Suíça, Estados Unidos, Alemanha e Austrália. Müller (2003) mostra que a competição fiscal é menor nos cantões suíços que adotam processos de democracia direta. $\mathrm{O}$ autor interpreta esse resultado com a hipótese de que cidadãos que podem intervir com processos de democracia direta nos gastos públicos 
aceitam tais gastos mais facilmente e, por isso, têm uma menor inclinação para deixar este cantão para morar em outro com uma carga tributária menor.

Dalton (2008), ao comparar os Estados dos EUA, chega a conclusões menos favoráveis. Em sua análise, afirma que iniciativas populares parecem reduzir ligeiramente a efetividade governamental ou, pelo menos, não têm um efeito substancialmente positivo sobre ela. Porém, admite que a efetividade não deveria ser o único critério de análise, afinal, a democracia em si não tem como primeiro objetivo ser efetiva. Dyck e Lascher (2009) confirmam estas observações céticas, também analisando o caso dos EUA. Expandindo a análise ao nível mundial, produz resultados menos semelhantes: Blume, Müller e Voigt (2009) estudaram todos os países do mundo (exceto os da África) e confirmam que países com o referendo obrigatório têm, em geral, menos gastos, em particular menos gastos na área de previdência e saúde. Porém, acreditam que países com iniciativas populares tendem a ter mais gastos e a ser mais corruptos. Nos resultados por eles apresentados, dívidas públicas e efetividade governamental não são influenciadas por processos de democracia direta. Em geral, os autores observaram que os efeitos dos processos de democracia são mais fortes quando são aplicados mais frequentemente e em países menos democráticos. Porém, segundo os autores, conclusões e comparações em escala mundial representam desafios metodológicos importantes, principalmente porque as instituições dos processos de democracia direta variam muito entre os países.

Há vários estudos que mostram que, em regimes com processos de democracia direta, os cidadãos sonegam menos impostos. Qual é o argumento teórico para esse comportamento? Processos de democracia direta permitem aos cidadãos influenciar os gastos públicos. Dessa forma, eles sabem melhor como os recursos estão sendo utilizados e podem direcionar os gastos conforme as suas preferências. Isso aumenta a probabilidade de eles entenderem para que serve o orçamento estatal e sentem-se mais à vontade para contribuir. Pommerehne e Weck-Hannemann (1996) foram os primeiros que mostraram que cantões suíços com processos de democracia direta são menos confrontados com a sonegação de impostos. Feld e Frey (2006) replicaram este achado. Torgler (2005) confirmou a mesma observação no nível municipal, também na Suíça. Blume, Müller e Voigt (2009), em uma análise mundial, confirmam que o uso do referendo diminui a evasão de impostos, porém, eles não observaram nenhum impacto significativo resultando do uso das iniciativas populares.

Em paralelo com os estudos sobre a sonegação de impostos, há um outro viés de pesquisa que aborda a relação entre processos de democracia direta e a formação de capital social. Nesse contexto, Freitag (2006) mostra, em uma comparação entre os cantões suíços, que de fato a disponibilidade de processos de democracia direta favorece a formação de capital social. Ainda um passo mais longe vão Frey e Stutzer (2000) que mostram, a partir de entrevistas com cidadãos suíços, que eles se consideram mais felizes na medida em que o cantão onde moram oferece processos de democracia direta.

Em suma, podemos concluir que os efeitos dos processos de democracia direta vão bem além da produção de decisões altamente legítimas. Embora existam numerosas pesquisas sobre os impactos positivos de processos de democracia direta na atividade econômica, na máquina pública e na sonegação de impostos, ainda faltam estudos que esclareçam devidamente a causalidade e comprovam estes estudos em análises comparativas. Ao mesmo tempo, é importante lembrar, como Gurza-Lavalle (2011, p. 42) afirma a respeito da parti- 
cipação em geral, que todas as coisas boas nunca vêm juntas. Sempre existem trade-offs com ganhos e perdas ao mesmo tempo.

\section{II.7. A questão dos custos dos processos de democracia direta}

Nossa discussão sobre os efeitos colaterais dos processos de democracia mostrou que além de os impactos desses mecanismos serem complexos, nem sempre são favoráveis para o desempenho de um sistema político. Nessa linha, exploramos, na presente seção, a questão dos custos dos processos de democracia direta. Será que os custos de consultas populares são tão altos que eles podem ser justificados no máximo em casos excepcionais, mas não como mecanismo regular? Esse argumento é levantado principalmente em debates populares; ele raramente pode ser encontrado na literatura científica. Na revisão bibliográfica do presente trabalho, não foi possível encontrar um estudo que aborde essa questão substancialmente. Seria ingênuo dizer que os custos dos processos de democracia direta não importam. Do ponto de vista conceitual, podemos distinguir dois tipos de custos: diretos e indiretos.

Custos diretos: Na execução de consultas populares, é preciso imprimir cédulas dos eleitores, comprar máquinas de votação, pagar salários dos oficiais envolvidos etc. Infelizmente, não existe nenhum estudo comparativo referente a esse tema. Considerando o fato de que os países adotam metodologias bem diversas, podemos esperar grandes diferenças nos gastos em consultas populares.

Custos indiretos: Constatamos que a inclusão de processos de democracia direta deixam um sistema político mais complexo. Decisões políticas podem demorar mais tempo. Por isso, há o argumento que consultas populares provocam custos indiretos. No contexto deste trabalho, nenhum estudo sobre esse tema foi encontrado. As dificuldades metodológicas para quantificar esses custos devem ser consideráveis.

Como já mencionamos no contexto dos efeitos colaterais dos processos de democracia direta, é preciso considerar tanto as perdas como também os ganhos. Nesse sentido, seria igualmente problemático focar somente os custos. Porém, sem conhecer os custos reais dos processos de democracia direta, é, por enquanto, impossível tirar conclusões substanciais.

\section{Conclusões}

A partir da pergunta de se é uma boa ideia consultar a população, não somente em eleições, mas também a respeito de questões específicas, que podem ser respondidas com um simples "sim" ou "não", fizemos uma revisão da literatura internacional. Nossa análise em torno de sete questões mostrou que a iniciativa popular, o plebiscito e o referendo podem ser complementos importantes para as instituições democráticas. Mas os benefícios desses mecanismos dependem tanto da sua regulamentação como também do contexto institucional e socioeconômico. Mais especificamente, constatamos que: (i) o medo dos minimalistas e as esperanças dos maximalistas democráticos são ambos exagerados. Os processos de democracia direta não são nem a praga de todos os males tampouco a cura para eles. A ambiguidade desses mecanismos mostrase também no comportamento dos cidadãos: por um lado, eles tendem a reivindicar direitos à participação, mas uma vez à disposição, nem sempre aproveitam deles; (ii) o perigo da tirania da maioria é teoricamente evidente. 
Empiricamente, encontram-se exemplos que confirmam essa hipótese. Porém, análises mais abrangentes não identificam maiorias opressivas e estáveis. Da mesma forma, questiona, empiricamente, a hipótese da tirania da minoria. Não existe nenhum exemplo empírico no qual uma minoria conseguiu manipular a agenda assim que a posição dela prevaleceu. Para o segundo argumento a favor da tirania da minoria, no qual ela consegue manipular a maioria por meio de recursos desproporcionais, é possível identificar exemplos empíricos; mas é igualmente possível identificar outros casos nos quais não foi possível influenciar substancialmente o resultado com campanhas caras. São precisos mais esforços de pesquisa para desvendar a importância dos recursos financeiros nas campanhas de processos de democracia direta; (iii) a introdução de processos de democracia direta pode tornar um sistema democrático representativo mais legítimo. Porém, a legitimidade adicional tem um preço: o processo político torna-se mais complexo. Somente quando os representantes enfrentam essa complexidade abertamente, podem-se esperar resultados positivos; caso contrário, o jogo político torna-se mais confuso e, com isso, menos democrático; (iv) a visão de que o cidadão é profundamente incompetente para participar de decisões políticas específicas não pode ser sustentada nem teórica nem empiricamente. Por outro lado, seria demasiadamente idealista argumentar que o cidadão dispõe, por natureza, de todas as competências necessárias para participar adequadamente em processos de democracia direta. $\mathrm{O}$ cidadão precisa ser educado e treinado para poder exercer seus direitos democráticos. Ele depende de informações e indicadores heurísticos de fontes que não são sistematicamente manipuladas. Isso requer uma legislação que limita excessos nas campanhas. A existência de processos de democracia direta pode ser um motivador crucial para que o cidadão interesse-se, informe-se e participe; $(v)$ o tamanho do eleitorado pode representar desafios substanciais na execução de consultas populares. Porém, esses desafios não são inerentes às consultas populares; eles surgem também em outros contextos institucionais de sociedades contemporâneas. Felizmente, existem cada vez mais meios técnicos que tornam a logística de consultas populares possível e confiável. A qualidade da deliberação depende muito menos do tamanho do eleitorado e muito mais das características socioeconômicas da população, da regulamentação das campanhas e de como as autoridades atuam em consultas populares; (vi) os efeitos dos processos de democracia direta vão bem além da produção de decisões legítimas. Embora existam numerosas pesquisas sobre os impactos positivos de processos de democracia direta na atividade econômica, na máquina pública e na sonegação de impostos, ainda faltam estudos que esclareçam devidamente a causalidade e que façam análises comparativas; (vii) apesar do fato de que em debates populares o argumento dos custos altos dos processos de democracia direta é levantado frequentemente, não existe nenhum estudo científico a esse respeito que confirme ou reprove a hipótese. Pesquisas futuras, de preferência comparativas, deverão esclarecer essa questão.

Considerando esses resultados, podemos tirar duas conclusões: em primeiro lugar, processos de democracia direta podem complementar as instituições representativas de uma maneira benéfica. Porém, na introdução e aplicação, devem ser consideradas questões da regulamentação em si (quem pode iniciar o processo? Quais temas podem ser abordados? Quem toma a decisão final? Quais são os prazos? etc.), do relacionamento com outras instituições (parlamentos, tribunais, administração, outras entidades federativas, direito internacional, etc.) e do contexto socioeconômico (escolaridade da população, acesso às mídias, etc.). Sem uma ponderação cautelosa de todos esses elementos, a introdução e aplicação de processos de democracia direta muito provavel- 
mente não contribuiria para a melhoria da democracia de uma entidade política. Em segundo lugar, ficou evidente, ao longo deste trabalho, que ainda existem várias e importantes lacunas na abordagem científica dos processos de democracia direta. Futuros esforços de pesquisa são precisos. O número crescente de consultas populares fornecerá a base empírica para essas investigações.

Rolf Rauschenbach (rolf@rauschenbach.ch) é doutor em Ciência Política pela Universität St. Gallen, Suíça, e pesquisador afiliado do Núcleo de Pesquisa de Política Pública NUPPs da Universidade de São Paulo

\section{Referências}

Abbink, K., 2006. Majority Rip-Off in Referendum Voting. Social Choice and Welfare, 26(1), pp. 1-21.

Aguiar-Conraria, L. \& Magalhães, P.C., 2010. Referendum Design, Quorum Rules and Turnout. Public Choice,144(1-2), pp. 63-81.

Altman, D., 2011. Direct Democracy Worldwide. Cambridge (UK): Cambridge University. . 2012. Does an Active Use of Mechanisms of Direct Democracy Impact Electoral Participation? Evidence from the U.S. states and the Swiss cantons. Local Governament Studies, 39(6), pp. 1-17.

Alves, M.L., 2010. Mecanismos de democracia direta e seus usos: 1988-2008. In IPEA. Estado, Instituições e Democracia: democracia. V. 2. Brasília: IPEA.

2011. Comparing Direct Democracy Processes in South. In IPSA-ECPR Joint Conference, São Paulo.

Amacher, R.C. \& Boyes W.J., 1978. Cycles in Senatorial Voting Behavior: Implications for the optimal frequency of elections. Public Choice, 33(3), pp. 5-13.

Anastásia, F.; Inácio, M. \& Novais, R., 2006. Referendo e democracia. Perdas e ganhos. In M. Inácio; R. Novais \& F. Anastásia, eds. Democracia e referendo no Brasil. Belo Horizonte: UFMG.

Anderson, C. \& Goodyear-Grant, E., 2010. Why Are Highly Informed Citizens Skeptical of Referenda? Electoral Studies, 29 (2), pp. 227-238.

Araujo Junior, A.F.; Gomes Reis, F.A.; Salvato, M.A. \& Shikida, C.D., 2007. "Dê-me segurança ou the dou um Não": em busca do eleitor mediano no referendo das armas. Revista Brasileira de Economia, 61(4), pp. 429-447.

Araújo, P.M. \& Santana, L., 2006. O referendo sobre o comércio das armas: processo decisório, representação popular na democracia brasileira. In M. Inácio; R. Novais \& F. Anastásia, eds. Democracia e referendo no Brasil. Belo Horizonte: UFMG.

Arrow, K.J., 1963. Social Choice and Individual Values. New Haven: Yale University.

Auad, D.; Pedrosa, J.C.H.; Martimiano, M.L. \& Tanganelli, R.F., 2004. Mecanismos de participação popular no Brasil. Plebiscito, referendo e iniciativa popular. Revista Brasileira de Direito Constitucional, 4, pp. 291-323.

Ávila de Brito, C.M., 2002. Mecanismos de democracia participativa no direito brasileiro. São Paulo. Dissertação de Mestrado. São Paulo: Universidade de São Paulo.

Arber, B.R., 1984. Strong Democracy: Participatory politics for a new age. Berkeley: University of California.

Batt, H., 2007. Der partizipative Staatsbürger. Über den Zusammenhang zwischen partizipatorischer Demokratie, Demokratiebewusstsein und Politischer Bildung. In D. Lange \& G. Himmelmann, eds. Demokratiebewusstsein: Interdisziplinäre Annäherungen an ein zentrales Thema der Politischen Bildung. Wiesbaden: VS Verlag für Sozialwissenschaften.

Bell, D.A., 1978. The Referendum: Democracy's barrier to racial equality. Washington Law Review, 54(1), pp. 1-29.

Benevides de Mesquita, M.V., 1991. A cidadania ativa: referendo, plebiscito e iniciativa popular. São Paulo: Ática.

Bengtsson, Å. \& Mattila, M., 2009. Direct Democracy and its Critics: Support for direct democracy and 'stealth' democracy in Finland. West European Politics, 32(5), pp. 1031-1048.

Blomberg, S.B.; Hess, G.D. \& Weerapana, A., 2004. The Impact of Voter Initiatives on Economic Activity. European Journal of Political Economy, 20(1), pp. 207-226.

Blume, L.; Müller, J. \& Voigt, S., 2009. The Economic Effects of Direct Democracy: A first global assessment. Public Choice, 140(3-4), pp. 431-461.

Bobbio, N., 1987. The Future of Democracy: A defense of the rules of the game. New York: Polity.

Böckenfröde, E.-W., 1976. Staat, Gesellschaft, Freiheit. Frankfurt am Main: Suhrkamp Verlag.

Boehmke, F.J. \& Bowen, D.C., 2010. Direct Democracy and Individual Interest Group Membership. The Journal of Politics, 72(3), pp. 659-671.

Bowler, S. \& Donovan, T., 1998. Demanding choices: Opinion, voting and direct democracy. Ann Arbor: The University of Michigan.

2002. Do Voters Have a Cue? Television advertisements as a source of information in citizen-initiated referendum campaigns. European Journal of Political Research, 41(6), pp. 777-793. 
Bowler, S.; Donovan, T. \& Karp, J.A., 2007. Enraged or Engaged? Preferences for direct citizen participation in affluent democracies. Political Research Quarterly, 60(3), pp. 351-362.

Bowler, S. \& Hanneman, R., 2006. Just How Pluralist is Direct Democracy? The structure of interest group participation in ballot proposition elections. Political Research Quarterly, 59(4), pp. 557-568.

Breuer, A., 2008. The Problematic Relation Between Direct Democracy and Accountability in Latin America: Evidence from the Bolivian case. Bulletin of Latin American Research,27(1), pp. 1-23.

Broder, D.S., 2000. Democracy Derailed: Initiative campaigns and the power of the money. New York: Hartcourt.

Budge, I., 1996. The New Challenge of Direct Democracy. Cambridge (MA): Polity.

Campbell, A.; Converse, P.; Miller, W. \& Stokes, D., 1960. The American Voter. New York: John Wiley and Sons.

Carneiro, R., 2001. A iniciativa popular no processo legislativo brasileiro. Brasília: Câmara dos Deputados.

Castro, M.C.P.S., 2006. Mídia e Política. Controversas relações. In M. Inácio; R. Novais \& F. Anastásia, eds. Democracia e referendo no Brasil. Belo Horizonte: UFMG.

Christin, T.; Hug, S. \& Sciarini, P., 2002. Interests and Information in Referendum Voting: An analysis of Swiss voters. European Journal of Political Research, 41(6), pp. 759-776.

Correa, I. \& Nunes, F., 2006. Democracia, poder legislativo e mecanismos institucionais participativos. In M. Inácio; R. Novais \& F. Anastásia, eds. Democracia e referendo no Brasil. Belo Horizonte: UFMG.

Cunningham, F., 2002. Theories of Democracy: A critical introduction. London: Routledge.

Dahl, R., 1989. Democracy and Its Critics. New Haven: Yale University.

Dalton, R. J., 2008. Direct Democracy and Good Governance: Does it matter? In S. Bowler \& A. Glazer, eds. Direct Democracy's Impact on American Political Institutions. New York: Palgrave MacMillan.

Dantas, H., 2008. Direitos políticos e participação popular: entre o desejo e a cultura política nacional. In S. Praça \& S. Diniz, eds. Vinte anos de Constituição. São Paulo: Paulus.

Donovan, T. \& Bowler, S., 1998. Direct Democracy and Minority Rights: An extension. American Journal of Political Science, 42(4), pp. 1020-1024.

Donovan, T.; Tolbert, C.T. \& Smith, D.A., 2011. Political Engagement, Mobilization and Direct Democracy. In K.L. Lindaman, ed. Direct Democracy: The struggle for democratic responsiveness and representation. New York: International Debate Education Association.

Dow, J.K., 2001. A Comparative Spatial Analysis of Majoritarian and Proportional Elections. Electoral Studies, 20(1), pp. $109-125$.

Dyck, J.J., 2009. Initiated Distrust. Direct democracy and trust in government. American Politics Research, 37(4), pp. 539568 .

Dyck, J.J. \& Lascher E.L., 2009. Direct Democracy and Political Efficacy Reconsidered. Political Behavior, 31(3), pp. 401427.

Ewert, B., 2007. Potenziale der direkten Demokratie in Lituaen, Slowenien und Ungarn unter besonderer Berücksichtigung der politischen Kultur. Frankfurt am Main: Peter Lang.

Feld, L.P. \& Frey, B.S., 2006. Tax Evasion in Switzerland: The roles of deterrence and tax morale. Institute for empirical research in economics. Working Paper Series, 284. Zurich: University of Zurich.

Feld, L.P. \& Kirchgässner, G., 2001. Does Direct Democracy Reduce Public Debt? Evidence from Swiss municipalities. Public Choice, 109(3-4), pp. 347-370.

2007. On the Economic Efficiency of Direct Democracy. In Z. Pállinger; B. Kaufmann; W. Marxer \& T. Schiller, eds. Direct Democracy in Europe. Developments and prospects. Wiesbaden: VS Verlag für Sozialwissenschaften.

Ferraiolo, K., 2011. Preserving the Initiative: State legislative response to direct democracy. In K.L. Lindaman, ed. Direct Democracy: The struggle for democratic responsiveness and representation. New York: International Debate Education Association.

Franklin, M.; Van Dereijk, C. \& Marsh, M., 1995. Referendum Outcomes and Trust in Government: Public support for Europe in the Wake of Maastricht. West European Politics, 18(3), pp. 101-117.

Freitag, M., 2006. Bowling the State Back In: Political institutions and the creation of social capital. European Journal of Political Research, 45(1), pp. 123-152.

Freitag, M. \& Vatter, A., 2006. Initiatives, Referendums and the Tax State. Journal of European Public Policy, 13(1), pp. 89112 .

Frey, B.S. \& Goette, L., 1998. Does the Popular Vote Destroy Civil Rights? American Journal of Political Science, 42(4), pp. 1343-1348.

Frey, B.S. \& Stutzer, A., 2000. Happiness Prospers in Democracy. Journal of Happiness Studies, 1, pp. 79-102.

Fuks, M. \& Novais, R., 2006. O referendo e a cobertura da imprensa. Uma análise do ambiente informacional. In M. Inácio; R. Novais \& F. Anastásia, eds. Democracia e referendo no Brasil. Belo Horizonte: UFMG.

Fuks, M. \& Paiva, D., 2006. Persuasão e deliberação sobre políticas públicas. A propaganda política no "Referendo das armas". In M. Inácio; R. Novais \& F. Anastásia, eds. Democracia e referendo no Brasil. Belo Horizonte: UFMG.

Galante Lesqueves, E.H., 2006. Democracia participativa: o futuro do Estado. Revista da Faculdade de Direito de Campos, 9 , pp. 555-591. 
Gallie, W. B., 1956. Essentially contested concepts. Proceedings of the Aristotelian Society, 56, pp. 167-198.

Garcia Navarro, A., 2004. Democracia semidireta: referendo, plebiscito, iniciativa popular e legislação participativa. Brasília: Universidade do Legislativo Brasileiro.

Gerber, E.R., 1999. The Populist Paradox: Interest group influence and the promise of direct legislation. Princeton: Princeton University.

2011. Legislatures, Initiatives and Representation: The effects of state legislative institutions on policy. In K.L. Lindaman, ed. Direct Democracy: The struggle for democratic responsiveness and representation. New York: International Debate Education Association.

Gerber, E. R.; Lupia, A. \& Mccubbins, M.D., 2011. When Does Government Limit the Impact of Voter Initiatives? The politics of implementation and enforcement. In K.L. Lindaman, ed. Direct Democracy: The struggle for democratic responsiveness and representation. New York: International Debate Education Association.

Gilland Lutz, K. \& Hug, S., 2010. Conclusion. In Eds. Financing Referendum Campaigns. New York: Palgrave MacMillan.

Grofman, B., 2004. Downs and Two-Party Convergence. Annual Review of Political Science, 7, pp. 25-46.

Grotz, F., 2009. Direkte Demokratie in Europa: Erträge, Probleme und Perspektiven der vergleichenden Forschung. Politische Vierteljahresschrift, 50(2), pp. 286-305.

Gurza-Lavalle, A., 2011. Participação: valor, utilidade, efeitos e causa. In C. Rocha \& R. Pires, eds. Efetividade das instituições participativas no Brasil: estratégias de avaliação. Brasília: IPEA.

Gurza-Lavalle, A. \& Isunza Vera, E., 2011. A trama da crítica democrática: da participação à representação e à accountability. Lua Nova, 84, pp. 95-139.

Habermas, J., 1998. Faktizität und Geltung: Beiträge zur Diskurstheorie des Rechts und des demokratischen Rechtsstaates. Frankfurt am Main: Suhrkamp Verlag.

2008a. Die Bürger sollen über Europa entscheiden. Tages-Anzeiger, 20.jun.

2008b. Die Schweiz muss sich an viele Regelungen anpassen. Entrevista concedida a Guido Kalberer, Tages-Anzeiger, 11.jun.

Haider-Markel, D.P.; Querze, A. \& Lindaman, K., 2011. Lose, Win or Draw: A reexamination of direct democracy and minority rights. In K.L. Lindaman, ed. Direct Democracy: The struggle for democratic responsiveness and representation. New York: International Debate Education Association.

Hajnal, Z. L.; Gerber, E. R. \& Louch, H., 2011. Minorities and Direct Legislation: Evidence from California ballot proposition elections. In K.L. Lindaman, ed. Direct Democracy: The struggle for democratic responsiveness and representation. New York: International Debate Education Association.

Hamilton, A.; Madison, J. \& Jay, J., 1961. The Federalist Papers. New York: Mentor.

Hibbing, J.R. \& Theiss-Morse, E., 2001. Stealth Democracy: Americas' beliefs about how government should work. New York: Cambridge University.

Higley, J. \& Mcallister, I., 2002. Elite Division and Voter Confusion: Australia's republic referendum in 1999. European Journal of Political Research, 41(6), pp. 845-861.

Hobolt, S.B., 2008. How Voters Decide in EU Referendums. In Democracy in and around Europe: Integration, innovation, illusion and ideology, Aarau.

Hug, S., 2002. Voices of Europe. Citizens, referendums and European integration. Lanham: Rowman \& Littlefield.

2004. Occurrence and Policy Consequences of Referendums: A theoretical model and empirical evidence. Journal of Theoretical Politics, 16(3), pp. 321-356.

2009. Some Thoughts about Referendums, Representative Democracy and Separation of Powers. Constitutional Political Economy, 20(3-4), pp. 251-266.

Inácio, M., 2006. Implementando a agenda presidencial? A participação do Poder Executivo no Referendo sobre as armas. In M. Inácio; R. Novais \& F. Anastásia, eds. 2006. Democracia e referendo no Brasil. Belo Horizonte: UFMG.

Inácio, M.; Novais, R. \& Anastásia, F., eds. 2006. Democracia e referendo no Brasil. Belo Horizonte: UFMG.

Jung, O., 2010. Zur Problematik des Beteiligungsquorums. In L.P. Feld; P.M. Huber; O. Jung; C. Welzel \& F. Wittreck, eds. Jahrbuch für direkte Demokratie 2009. Baden-Baden: Nomos.

Jung, S., 2001. Die Logik direkter Demokratie. Opladen: Westdeutscher Verlag.

Kahn, M.E. \& Matsusaka, J.G., 1997. Demand for Environmental Goods: Evidence from voting patterns on California initiatives. Journal of Law and Economics, 40(1), pp. 137-174.

Kirchgässner, G., 2008. Direct Democracy: Obstacle to reform? Constitutional Political Economy, 19(2), pp. 81-93.

Kobach, K., 1993. The Referendum: Direct democracy in Switzerland. Vermont: Dartmouth.

Lapuente, V., 2011. Principal-Agent Theory. In B. Badie; D. Berg-Schlosser \& L. Morlino, eds. International Encyclopedia of Political Science. Oakland: Sage.

Leduc, L., 2003. The Politics of Direct Democracy: Referendums in global perspective. Ontario: Broadview.

Lupia, A., 1994. The Effect of Information on Voting Behavior and Electoral Outcomes: An experimental study of direct legislation. Public Choice, 78(1), pp. 65-86. 
Lupia, A. \& Mccubbins, M., 1998. The Democratic Dilemma: Can citizens learn what they need to know? Cambridge (UK): Cambridge University.

Lutz, G., 2006. The Interaction between Representation and Direct Democracy in Switzerland. Representation, 42(1), pp. 4557

2007. Low Turnout in Direct Democracy. Electoral Studies, 26(3), pp. 624-632.

Maravall, J.M., 1999. Accountability and Manipulation. In A. Przeworsky; S.C. Stockes \& B. Manin, eds. Democracy, Accountability and Representation. New York: Cambridge University.

Matsusaka, J.G., 2004. For the Many or the Few: The initiative, public policy and American democracy. Chicago: University of Chicago.

2005. The Eclipse of Legislatures: Direct Democracy in the 21st Century. Public Choice, 124(1), pp. 157-177

2011. Direct Democracy Works. In K.L. Lindaman, ed. Direct Democracy: The struggle for democratic responsiveness and representation. New York: International Debate Education Association.

Mathews, J., 2006. The People's Machine. Arnold Schwarzenegger and the rise of blockbuster democracy. New York: Public Affairs.

Mendelsohn, M. \& Parkin, A., 2001. Referendum Democracy. Citizens, Elites and Deliberation in Referendum Campaigns. Basingstoke: Palgrave Macmillan.

Mendes Vitale Ramos, D.C., 2007. Representação política e participação: Reflexões sobre o déficit democrático. Revista Katál, 10(2), pp. 143-153.

Mendonça, R.F., 2009. A cooperação na deliberação pública: um estudo de caso sobre o referendo da proibição da comercialização de armas de fogo no Brasil. Dados, 52(2), pp. 507-542

Menezes Boelhouwer, D. \& Dias, M.R., 2009. Campanha política e mídia no referendo das armas. In $33^{\circ}$ Encontro Anual da Anpocs, Caxambu.

Meredith, M., 2009. The Strategic Timing of Direct Democracy. Economics \& Politics, 21(1), pp. 159-177.

Möckli, S., 1994. Direkte Demokratie. Ein Vergleich der Einrichtungen und Verfahren in der Schweiz und in Kalifornien, unter Berücksichtigung von Frankreich, Italien, Dänemark, Irland, Österreich, Liechtenstein und Australien. Bern: Haupt Verlag.

Moisés, J.A., 1990. Cidadania e participação. Ensaio sobre o plebiscito, o referendo e a iniciativa popular na nova Constituição. São Paulo: Marco Zero.

Müller, C., 2003. Steuerwettbewerb und direkt Demokratie in den Schweizer Kantonen. Swiss Political Science Review,9(2), pp. 107-120.

Neidhart, L., 1970. Plebiszit und pluralitäre Demokratie. Eine Analyse der Funktion des schweizerischen Gesetzesreferendums. Bern: Francke.

Neijens, P. \& De Vreese, C., 2009. Helping Citizens Decide in Referendums: The moderating effect of political sophistication on the use of the information and choice questionnaire as a decision aid. Public Opinion Quarterly, 73(3), pp. 521536.

Pateman, C., 1970. Participation and Democratic Theory. Cambridge (UK): Cambridge University.

Peterlevitz, T., 2011. Adding Direct Democracy Processes to an Assessment of Political Participation. In IPSA-ECPR Joint Conference, São Paulo.

Pettit, P., 2003. Deliberative Democracy, the Discursive Dilemma and Republican Theory. In J. Fishkin \& P. Laslett, eds. Philosophy, Politics and Society. New York: Cambridge University.

Pitkin, H.F., 1967. The Concept of Representation. Berkley: University of California.

Pommerehne, W.W., 1983. Private versus Öffentliche Müllabfuhr: Nochmals betrachtet. Public Finance Analysis, 41(3), pp. 466-475.

Pommerehne, W.W. \& Weck-Hannemann, H., 1996. Tax Rates, Tax Administration and Income Tax Evasion in Switzerland. Public Choice, 88(1-2), pp. 161-170.

Rauschenbach, R., 2010. Mit direktdemokratischen Verfahren zu postkonventionellen politischen Kulturen: Theoretische Überlegungen anhand von Jürgen Habermas und Lawrence Kohlberg.Berlin: Duncker \& Humblot. . 2011. Processes of Direct Democracy in Brazil: A review. C2D Working Papers Series, 40, pp. 1-16. Zurich: Centre for Research on Direct Democracy.

2012. Postconventional Political Cultures via Processes of Direct Democracy: Theoretical considerations based on Jürgen Habermas and Lawrence Kohlberg. Swiss Political Science Review, 18(4), pp. 477-497.

Rocha Pires, R., ed. 2011. Efetividade das instituições participativas no Brasil: estratégias de avalição. Brasília: IPEA.

Sartori, G., 1987. The Theory of Democracy Revised. Chatham: Chatham House.

Schuck, A.R.T. \& De Vreese, C.H., 2011. Public support for referendums: The role of the media. West European Politics, 34 (2), pp. 181-207.

Schumpeter, J.A., 1962. Capitalism, Socialism and Democracy. London: Allen and Unwin.

Selb, P., 2008. Supersized Votes: Ballot length, uncertainty, and choice in direct legislation elections. Public Choice, 135, pp. 319-336. 
Serdült, U., 2007. Direct Democracy in Switzerland and its Discontents. In Conferencia Internacional Direct Democracy in Latin America, Buenos Aires.

Setälä, M., 1999. Referendums and Democratic Government: Normative theory and the analysis of institutions. London: Palgrave-MacMillan.

Smith, M.A., 2002. Ballot Initiatives and the Democratic Citizen. The Journal of Politics, 64(3), pp. 892-903.

Suski, M., 1993. Bringing in the People: A comparison of constitutional forms and practices of the referendums. Dordrecht: Martinus Nijhoff.

Svensson, P., 2007. Five Danish Referendums on the European Community and European Union: A critical assessment of the Franklin thesis. European Journal of Political Research,41(6), pp. 733-750.

Tolbert, C.J., 2003. Direct Democracy and Institutional Realignment in the American states. Political Science Quarterly, 118 (3), pp. 467-489.

Tolbert, C.J. \& Smith, D.A., 2005. The Educative Effects of Ballot Initiatives on Voter Turnout. American Politics Research, 33(2), pp. 283-309

Torgler, B., 2005. Tax Morale and Direct Democracy. European Journal of Political Economy, Kidlington, 21(2), pp. 521531.

Vatter, A., 1997. Die Wechselbeziehungen von Konkordanz- und Direktdemokratie. Politische Vierteljahresschrift, 38(4), pp. 743-770.

2002. Kantonale Demokratien im Vergleich. Entstehungsgründe, Interaktionen und Wirkungen politischer Institutionen in den Schweizer Kantonen. Opladen: Leske + Budrich.

Viega, L.F. \& Avi Dos Santos, S., 2008. O referendo das armas no Brasil. Estratégias de campanha e comportamento eleitoral. Revista Brasileira de Ciências Sociais, 23(66), pp. 59-77.

Vogel, L.H., 2006. Atualização de estudo sobre "participação popular nas decisões legislativas”. Consultoria. Brasília: Câmera dos Deputados.

Wagschal, U., 2011. Direct Democracy and Public Policymaking. In K.L. Lindaman, ed. Direct Democracy: The struggle for democratic responsiveness and representation. New York: International Debate Education Association.

Weber, M., 1985. Wirtschaft und Gesellschaft. Tübingen: Mohr.

Zart, R.E., 2007. O poder constituinte derivado e a sistemática das emendas constitucionais na Constituição federal de 1988. Dissertação de Mestrado. Rio do Sul: Universidade do Vale de Itajaí.

\begin{abstract}
There is an ongoing debate on whether processes of direct democracy, such as the popular initiative, plebiscite and referendum are helpful in the political decision making process. On the one hand, there are authors arguing that these institutions slow the political game down, turn it more expensive, confusing and illegitimate; others defend the contrary position, arguing these mechanisms are fundamental to the citizen and the quality of democracy. The present study examines the following seven issues of this matter, based on theoretical consideration and empirical research: 1 . Democratic minimalism and maximalism; 2 . Competition between majority and minority; 3. Competition between representative institutions and processes of direct democracy. 4 . Competence of citizens; 5. Side effects of processes of direct democracy; 6 . Size of electorate; 7. Costs of processes of direct democracy. The analysis is based on a review of national and international literature. The study shows that processes of direct democracy can be complementary to institutions of representative democracy. The well functioning of popular initiatives, plebiscites and referendums does not only depend on their regulation, but also on the performance of the other political institutions as well as the socio-economical situation of a country. The study allows to deepen the debate on processes of direct democracy in Brazil.
\end{abstract}

KEYWORDS: Democratic institutions; processes of direct democracy; popular initiative; plebiscite; referendum; representation 